\title{
Teachers' Job Satisfaction and Personal Life Balance Aspects
}

\author{
Genute Gedviliene ${ }^{1} \mathrm{PhD}$; Rasa Didziuliene ${ }^{2}$ \\ Vytautas Magnus University, Lithuania \\ genute.gedviliene@vdu.lt1 ; rasa.didziuliene@gmail.com²
}

\begin{abstract}
Seeking personal fulfilment and self-realisation, and wishing to contribute to social well-being are important for teachers. Social, economic and technological changes in the contemporary society bring about changes in how the labour market and educational institutions operate. Previous research has shown that the balance between personal well-being and job satisfaction is useful for the organisation itself. However, some managers of educational institutions in Lithuania are still slow in implementing the measures to ensure the balance. The aim of the research is to reveal the interaction between the balance in personal life and job satisfaction of teachers. Analysis of scientific literature was selected for the theoretical explanation of the research problem as well as a quantitative research method (questionnaire) was selected for the empirical research. The current survey has established the main factors affecting job satisfaction, the main of which is the type of work, relationships with colleagues and trust in the organisation. The research showed that the most effective measures, which affect the balance between the teacher's personal well-being and job satisfaction, as indicated by the respondents was the opportunity for flexible working time, quality workplace and duration of working hours (part-time work).
\end{abstract}

Keywords: personal well-being, job satisfaction, school education.

\section{Introduction}

As a result of fast development of technology, work specifics changes; within the context of social changes, the volume of knowledge and information increases; and economic changes increase the scope of work per employee. Under these circumstances, not only the choice of a professional career that becomes relevant, but also work-life balance of teachers. Educators find reconciling such things as growing demands of their management, their workload and personal time increasingly more difficult. According to various studies, job satisfaction is responsible for greater motivation, dedication to the job, lower employee turnover and contributes to a better quality of life of individuals. In addition to their professional activity, employees have many other responsibilities and needs (family, friends, and hobbies) which require time. Work-life balance means the reconciliation of all these duties and needs with the main professional activity. The balance in this case does not mean that equal time must be devoted to the said variable, but that every teacher should have the opportunity to combine these factors. The opportunity to maintain work-life balance provided by their management increases efficiency, job satisfaction and loyalty to the organisation. The aim of the research is to reveal the interaction between the balance in personal life and job satisfaction of teachers.

\section{Methodology}

Research methods: Analysis of scientific literature was selected for the theoretical explanation of the research problem as well as a quantitative research method (questionnaire) was selected for the empirical research. The survey aimed to identify the teachers' attitude personal experience and the situation at educational organisations relating to the pursuit of balance between personal well-being and job satisfaction.

The survey hypothesis: work-life balance leads to changes in job satisfaction. When testing the hypothesis, the aim was to identify whether the respondents were satisfied with each identified job satisfaction factor.

The questionnaire consists of four parts. Two types of questions have been used: closed-ended questions with multiple choices and statements with scale responses (the choices for answers range between 1 and 10, where 1 means strongly disagree and 10 means strongly agree). The questionnaire was divided into four parts: job satisfaction (questions 1-4); work-life balance (questions 5-6); flexible work opportunities (questions 7-9) and general information (matters 10-15).

Organisation of the survey. Teachers from 13 Lithuanian schools agreed to participate in the survey. There was a total of 478 respondents, of which $72 \%$ were women and $28 \%$ men. The survey was carried 
out in April 2018. Data are generalized, synthesised and displayed graphically (Vogt, 2005). The results were analysed using the statistical, comparative and content analysis methods. Statistical analyses were performed using the Statistical Package for the Social Sciences (SPSS 24) for Windows.

\section{Results and Discussion}

\section{The concept of the balance between personal well-being and job satisfaction and its importance}

The concept and understanding of job satisfaction have evolved over time depending on the actual issues of the period, context and other factors. Job satisfaction can be defined as human condition where a person either likes or dislikes his work. One of early definitions of job satisfaction was provided by M. Beer (1964) who maintained that it was employees' attitude towards the company, fellow workers and other psychological objects in the work environment. In other words, job satisfaction is an individual feeling of every human being with respect to his/her workplace, which depends on the wishes of the employee and compliance of the needs with the actual satisfaction of the needs.

There are several theories which explain the importance of the balance between personal well-being and job satisfaction. In literature it is explained in two ways - as the state of an individual or as a way to achieve this state.

The authors who explain the concept of the balance between personal well-being and job satisfaction as the state provide a definition common to all social groups. Researchers describe it as the state of equilibrium achieved by an employee, where he is able to meet the demands of both his work and personal life (Rama Devi, Nagini, 2013; Lockwood, 2003; Khallash, Kruse, 2012). L. Blazovich, K.T. Smith and L.M. Smith (2014) maintain that the balance between personal well-being and job satisfaction is the distribution of a person's time between work duties and other pursuits (family, hobbies and other social needs).

R. Baltusite and I. Katane have studied the successfulness of a teacher's career. The educator's profession is not only a profession, but also a mission. A successful teacher is the one who perceives his or her professional activities as calling, where the main essence is serving to the nation and mankind. The research has shown that the most important indicators of advantages of a teacher's profession was self-development, working with the youth, creative work and satisfaction (Baltusite, Katane, 2017, 32).

Despite of the awareness of mission of teacher and job satisfaction granted by association with students the situation of educators is quite complicated. On the one hand the educator faces very high demands from society and on the other hand the educator meets lack of uniform demands and values in school and among parents, the low esteem of teacher's profession and low student motivation to learn, serious problems of discipline in school. The above does not contribute to job satisfaction and life balance. Teachers need regular and deep support, that would offer a transformative learning environment characterised by reflection and self-evaluation (Ergle, Rutka, 2016).

For the purposes of this article the personal well-being of teachers will be considered to be allocation of time for the satisfaction of the needs related to the family, hobbies and other social activities.

Some authors, however, include in the definition of work-life balance not only the employee's perspective, but also that the management. N.R. Lockwood (2003) provides a more accurate and concrete description taking into account social characteristics of the individual. The author maintains that the concept of work-life balance has different meanings for different groups of people: from an employee's viewpoint, it is a dilemma of managing work obligations and personal/family responsibilities; from an employer's viewpoint, it is a challenge of creating a supportive working environment for employees so they can focus on their jobs. Thus, based on the analysis of the concept of the balance between job satisfaction and personal well-being as a state it becomes clear that an individual's social and marital status and the position held in a company are some of the important characteristics in researching and discussing this phenomenon.

H. Kumar and S.K. Chakraborty (2013) maintain that in order an employee would feel happy and motivated to work, his focus should not only be on the organisation, but also on the society. This is difficult to implement, if the employee does not have the possibility to maintain the balance between these activities. In his Ecological Systems Theory U. Bronfenbrenner (Bronfenbrenner, 1989; Whinston, Cinamon, 2015) provides a scientific justification for the above claim. The Ecological Systems Theory 
distinguishes four systems (micro, meso, exo and macro) surrounding individuals that affect each another (Figure 1).

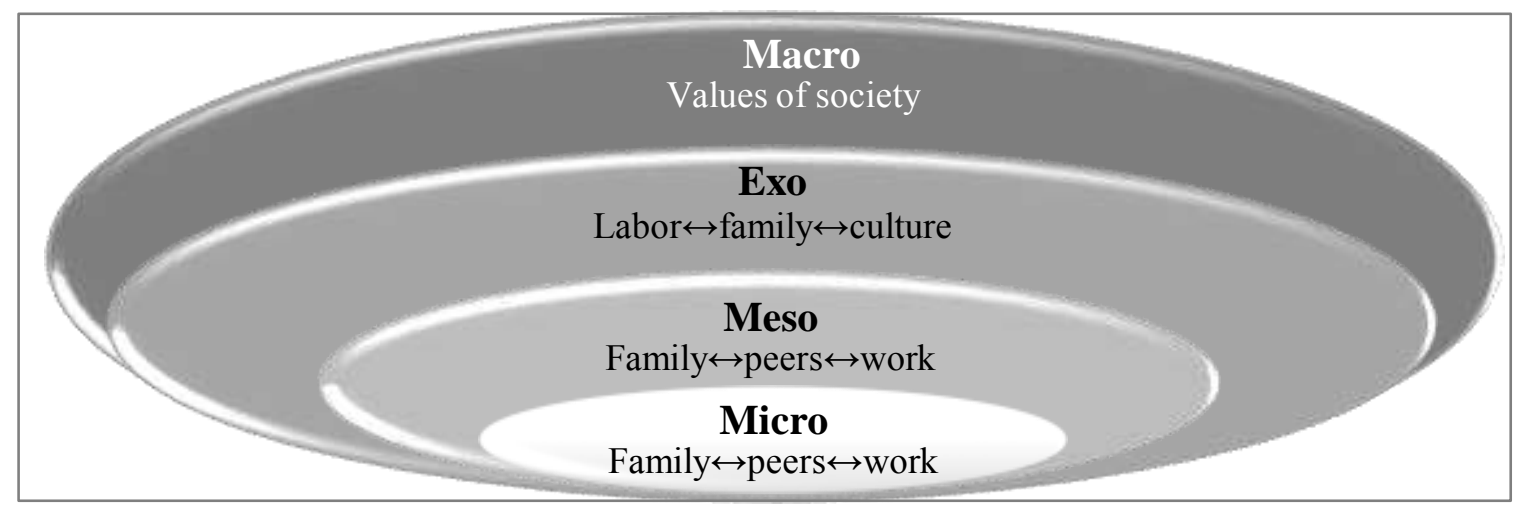

Figure 1. Elements of U. Bronfenbrenner's Ecological Systems Theory. Source: prepared by the authors on the basis of U. Bronfenbrenner (1989) and S.C. Whinston, R.G. Cinamon (2015).

According to U. Bronfenbrenner (1989) systems can be explained as follows:

- microsystem - family and work. All the elements which take part in an individual's life can be attributed to this system. On the basis of the conclusion made earlier concerning the definition of personal life, this system may include hobbies and other public pursuits.

- mesosystem refers to the interactions between microsystems. The mesosystem includes the component of balance between job satisfaction and personal well-being, because one element of the system (work) affects the other element (personal life) either negatively or positively.

- exosystem - environment (organisational culture, family culture) which affects an individual while the individual has little or no effect on the environment.

- macrosystem - the largest system in which an individual life affects labour, family and other values.

Thus, according to the Ecological Systems Theory, the teacher inevitably experiences either positive or negative interaction between elements of the microsystem in which s/he lives within the mesosystem. The teacher, like any individual, lives in the encompassing macro system where the conditions not always depend on the individual. The balance between certain elements of life is not only the teacher's problem, but also the problem of the administration of the educational institution that the teacher represents.

P.J. Dewe, M.P. O'Driscoll and C.L. Cooper (2010) distinguishes five different approaches in order to explain the relationship between job satisfaction and personal well-being:

- segmentation model - work and personal life are two distinct domains of life which do not have anything in common;

- spillover model - these two factors may influence one another in positive and negative way;

- compensation model - whatever is lacking in one domain in the sense of needs or satisfaction, can be compensated in the other domain;

- instrumental model - one domain facilitates activities in the other domain;

- conflict model - excessive needs in all domains of life may force individuals to make difficult choices, which may cause certain conflicts.

Mutual interaction between work and personal life are mainly examined by researchers within the context of the conflict theory. Based on this theory, L.T. Brummelhuis and T. van der Lippe (2010) claimed that the use of human time and energy only for one role leaves no time for other roles. This happens because, according to the conflict theory, the relationship between family and work is best expressed as a zero-sum game, because the human time and energy are finite resources. To sum up, it can be said that time and energy dedicated to the family cannot be devoted to work and vice versa. The authors speak only about the work-family conflict, however the same can be adapted to the conflict between personal well-being (not only family) and job satisfaction.

So far, the impact of technology has not been considered to be an important factor for the topic in question (Haeger, Lingham, 2014), but it is specifically technological upgrade, which has led to the emergence and popularisation of new forms of work that have fuelled the conflict between work and 
personal life. Laptops, mobile phones and the internet made flexible working hours more appropriate and more effective in terms of costs (Greenblatt, 2002). Thus, the rapidly growing technological advance and flexible work opportunities blur the boundaries between leisure time and work, while at the same time increasing the likelihood of side effects on the quality of life (Ilies, Wilson, Wagner, 2009; Bell, Rajendran, Theiler, 2012). The spill over of work problems into the family and vice versa gives rise to the problem of how teachers can combine and separate these two major aspects of life.

J.H. Greenhouse and G.N. Powell (2006) offer the theory of work-family enrichment. According to the authors, enrichment occurs where the resources derived by performing one role encourage better performance of another role. This theory reveals best why an educational institution must help teachers combine their social roles.

On the basis of the theory of roles of S.C. Whinston and R.G. Cinamon (2015) claimed that every role has a certain market demand limited by finite resources. Time and energy, which are limited, can be considered such finite resources. There is a need to distribute one's personal life priorities between the roles. Failure to identify priorities or to distribute equal amount of time between all roles causes conflict between elements of these roles (mesosystem).

\section{Empirical investigation of the personal well-being and job satisfaction}

One of the objectives of the study was to identify whether the respondents were satisfied with each identified job satisfaction factor. It was also sought to clarify whether an individual had a problem to combine the needs of work and personal life and how he manages to reconcile them. Finally, following the evaluation of the job satisfaction and work-life balance of the respondents it was sought to find a connection between these two variables.

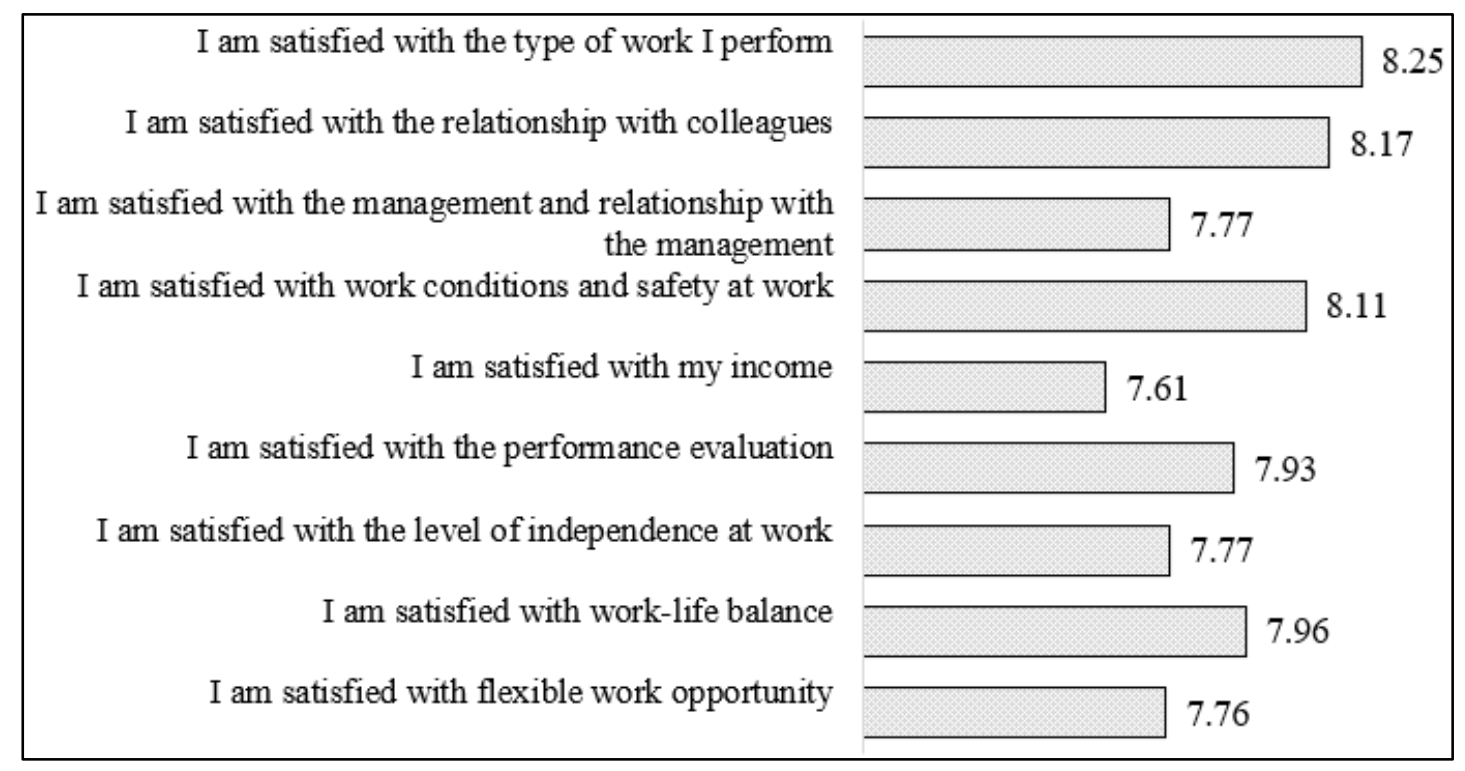

Figure 2. Job satisfaction of respondents (the mean values of the responses $1 \leq \mathrm{M} \leq 10$ ).

Part one of the questionnaire consists of the questions regarding job satisfaction factors (mean scores are provided in Figure 2). The results show that the teachers who have participated in the survey are sufficiently satisfied with their work. The respondents were least satisfied with their income (7.61), flexible work opportunities at school (7.76), level of independence (7.77) and management and relationship with the management (7.77). Although these job satisfaction factors scored lowest, it cannot be said that teachers are thoroughly dissatisfied with these factors (the score is higher than the average [5]). The work-life balance indicator scored 7.96. Educators are most satisfied with the type of work they perform (8.25) and their relationship with colleagues (8.17). Thus, it can be said that teachers are pleased with what they do.

Two statements provided to the respondents entailed interaction between work-life balance and job satisfaction. The mean score in the case of the first statement "Work-life balance is important for longterm job satisfaction" was 9.08 and in the case of the second statement "I have the opportunity to reconcile work with my personal life needs, I feel more satisfied with my work" -9.19 . The data obtained 
allow to assume that for teachers the effect of work-life balance on job satisfaction is significant. The second part of the questionnaire assesses the problem of the presence/absence of work-life balance in the life of respondents (Figure 3).

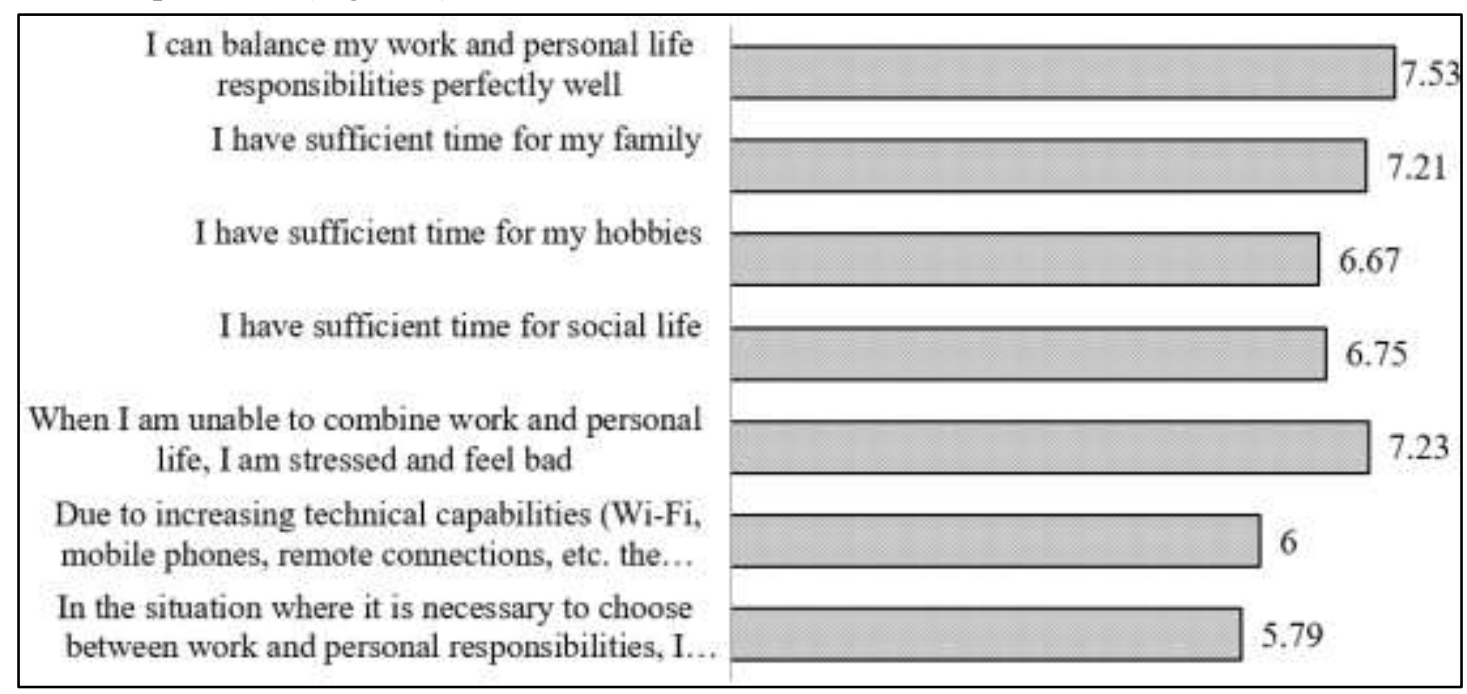

Figure 3. Work-life balance of the respondents (the mean values of the responses $1 \leq \mathrm{M} \leq 10$ ).

The mean scores for the statements (Figure 3) show that the participants of the survey manage to balance their work and personal life quite well (7.53). However, although the respondents maintain that they manage to combine their work and personal life perfectly well, the scores for the statements concerning the time dedicated to the family, hobbies and social life are lower. These three statements reveal the priorities in the respondents' life - they dedicate least time for hobbies (6.67) and social life (6.75). Family remains in the first place, although the respondents do not feel they spend sufficient time for it (7.21).

A quite interesting score was obtained in the case of the statement concerning prioritising work or personal life - the statement "In the situation where it is necessary to choose between work and personal responsibilities, I prioritise work" scored 5.79, which is higher than the average. Although the respondents would prioritise work over personal life, the statement "When I am unable to combine work and personal life, I am stressed" scored 7.23, which is a sufficiently high score and leads to the conclusion that choosing work is not always pleasant.

In part one and two (questions 2 and 7) the respondents were asked questions concerning the factors that are likely to interfere with maintaining work-life balance. The effect of these factors on job satisfaction and work-life balance was assessed (Figure 4).

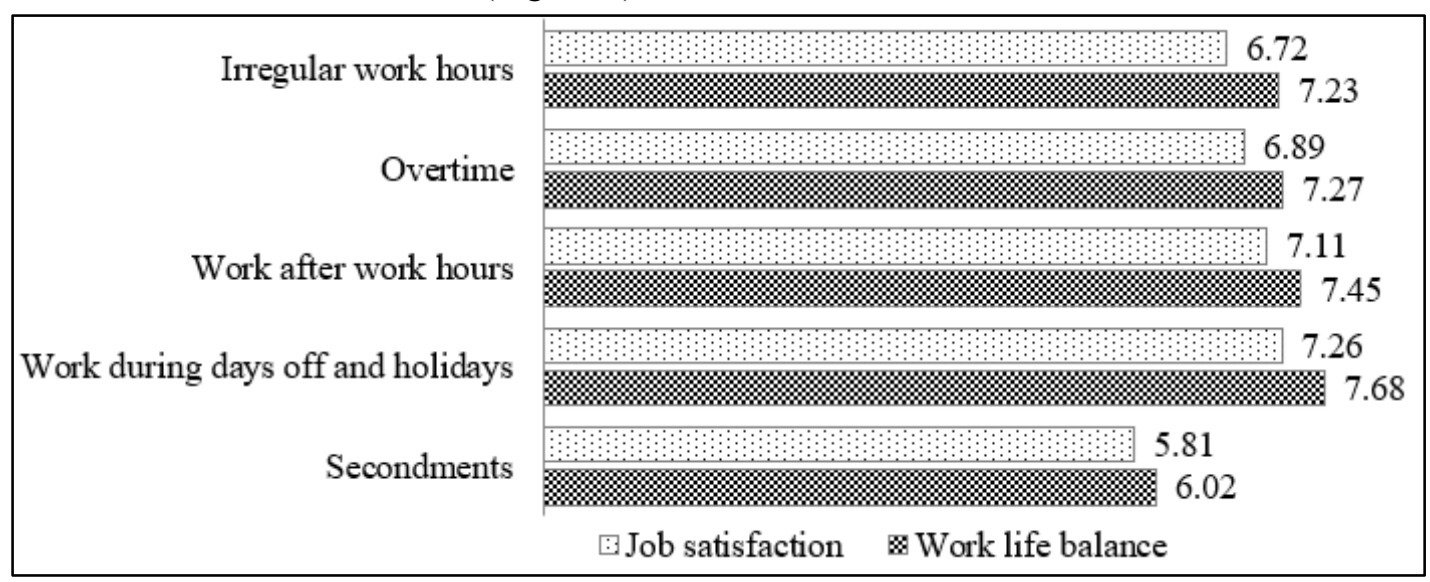

Figure 4. How factors which interfere with work-life balance affect the balance between personal life and job satisfaction of teachers (the mean values of the responses $1 \leq M \leq 10$ ).

Factors which interfere with work-life balance (Fig. 4) adversely affect work-life balance rather than job satisfaction. Work during days off and holidays was assessed by the respondents as the most negative factor (7.86) for work-life balance. Work at home after work hours (7.45), overtime (7.27) and irregular 
working hours (7.23) were assessed fairly negatively too. Secondments were least negatively assessed by the respondents within both the context of job satisfaction and work-life balance. This may be due to the fact that not all teachers have an opportunity to travel for work and rather view this as entertainment although this is their working time.

When testing the hypothesis, the aim was to identify whether the respondents were satisfied with each identified job satisfaction factor (Table 1).

Table 1

Correlation of the scores for work-life balance factors and job satisfaction factors

(Pearson correlation coefficient)

\begin{tabular}{|l|c|c|c|c|}
\cline { 2 - 5 } \multicolumn{1}{|c|}{ Job satisfaction factors } & \multicolumn{4}{c|}{ Work-life balance variables } \\
\hline Type of work & $\begin{array}{c}\text { I can balance my } \\
\text { work and personal } \\
\text { life responsibilities } \\
\text { perfectly well }\end{array}$ & $\begin{array}{c}\text { I have } \\
\text { sufficient } \\
\text { time for my } \\
\text { family }\end{array}$ & $\begin{array}{c}\text { I have } \\
\text { sufficient time } \\
\text { for my } \\
\text { hobbies }\end{array}$ & $\begin{array}{c}\text { I have } \\
\text { sufficient time } \\
\text { for social life }\end{array}$ \\
\hline Relationships with colleagues & $0.219^{* *}$ & $0.213^{* *}$ & $0.222^{* *}$ & $0.209^{* *}$ \\
\hline Management & $0.291^{* *}$ & $0.205^{* *}$ & $0.211^{*}$ & $0.245^{* *}$ \\
\hline Working conditions and safety & $0.333^{* *}$ & $0.243^{* *}$ & $0.247^{* *}$ & $0.277^{* *}$ \\
\hline Income & $0.281^{* *}$ & $0.238^{* *}$ & $0.249^{* *}$ & $0.237^{* *}$ \\
\hline Performance evaluation & $0.213^{* *}$ & $0.198^{* *}$ & $0.183^{* *}$ & $0.169^{* *}$ \\
\hline Level of independence & $0.304^{* *}$ & $0.239^{* *}$ & $0.245^{* *}$ & $0.208^{* *}$ \\
\hline Work-life balance & $0.174^{* *}$ & $0.146^{*}$ & $0.141^{*}$ & $0.162^{*}$ \\
\hline Flexible work opportunities & $0.400^{* *}$ & $0.341^{* *}$ & $0.323^{* *}$ & $0.366^{*}$ \\
\hline
\end{tabular}

${ }^{*} \mathrm{p}<0.05 ; *{ }^{*} \mathrm{p}<0.01$ (Source: prepared by the authors)

After performing the correlation analysis, no strong links between variables were observed. Very weak correlation between the satisfaction of the respondents with their management and work-life balance was established. The better the individual gets on with his superiors, the better he combines his work and personal life responsibilities. This could be explained by more humane relationships between the employee and the manager, where the manager understands the employee's personal concerns and allows the employee to deal with them without causing the employee additional stress about it.

The better the individual is able to combine his work-life responsibilities, the more time he has for his family, hobbies and social life, the more he is satisfied with his work-life balance. The correlation between these factors, albeit very weak, proves this. Also, it is important to note that the more an individual is satisfied with flexible working, the better he combines his work and personal life responsibilities and has time for social life. Thus, it can be said that flexible work opportunities open the way for those aspects of life for which otherwise no time is left.

\section{Evaluation of the survey results}

During the survey assumptions were made that work-life balance leads to changes in job satisfaction of teachers and flexible working results in positive changes in personal well-being and job satisfaction. Based on these assumptions, the survey hypothesis was proposed work-life balance leads to changes in job satisfaction. The survey showed that teachers are satisfied with their work and reconcile their worklife obligations sufficiently well. Such results could have caused insignificant correlations between these two variables. The more teachers reconcile their work-life responsibilities, the more time they dedicate to the family, hobbies and social life, the more they feel satisfied with work-life balance as one of the job satisfaction factors.

The respondents whose work involves flexible working feel greater satisfaction with their relationship with the management, their working conditions, and evaluation of performance compared to the teachers who do not have the opportunity of flexible work. During the survey it was established that flexible working 
hour arrangement helps the balance between personal well-being and job satisfaction: teachers can dedicate time for professional development and career without neglecting the family and personal hobbies. It can be assumed that the more teachers are satisfied with the flexible work opportunities, the better they combine their work and personal life responsibilities and have time for social life. It can be said that the flexible work opportunities open the way for those aspects of life for which otherwise no time is left.

\section{Conclusions}

The analysis of the concept and meaning of work-life balance allowed approaching this phenomenon from several different perspectives: the conflict and supplementary factor. It can be concluded that, if work-life balance is in the conflict state and the teacher is not satisfied with his work, the educational institution may suffer adverse consequences (employee turnover, stress).

The analysis of the survey on work-life balance and job satisfaction revealed statistics on the real situation concerning this problem in Lithuania. On the basis of the results of the empirical research, the main factors affecting job satisfaction of teachers were identified, the most prominent of which is the type of the work, relationships with colleagues and trust in their educational institution.

After performing the empirical research, the most effective measures which affect the balance between personal well-being and job satisfaction of teachers were identified. The respondents specified the opportunity for flexible working time, quality workplace and duration of working hours (part-time work).

\section{Bibliography}

1. Baltusite R., Katane I. (2017). The Modern Teacher's Career. In V. Dislere (Ed.), The Proceedings of the International Scientific Conference Rural Environment. Education. Personality (REEP), 10. Jelgava: LLU TF, 30-39. Retrieved from http://llufb.llu.lv/conference/REEP/2017/Latvia-Univ-Agricult-REEP2017 proceedings.pdf

2. Beer M. (1964). Organizational size and job satisfaction. The Academy of Management Journal, 7(1), 34-44.

3. Bell A.S., Rajendran D., Theiler S. (2012). Job stress, wellbeing, work-life balance and work-life conflict among Australian academics. Electronic Journal of Applied Psychology, 8(1), 25-37.

4. Blazovich J.L., Smith K. T., Smith L.M. (2014). Employee-friendly companies and work-life balance: is there an impact on financial performance and risk level? Journal of Organizational Culture, Communications and Conflict, 18(2), 1-14.

5. Bronfenbrenner U. (1989). Ecological systems theory. Annals of child development, 6, 187-249.

6. Brummelhuis L.T., van der Lippe T. (2010). Effective work - life balance support for various household structures. Human Resource Management, 49 (2), 173 - 193.

7. Dewe P.J., O'Driscoll M.P., Cooper C.L. (2010). Coping with Work Stress: A Review and Critique. West Sussex, UK: John Wiley and Sons.

8. Ergle L., Rutka L. (2016). The Theoretical Nature and Practical Necessity of Pedagogical Supervision. In V. Dislere (Ed.), The Proceedings of the International Scientific Conference Rural Environment. Education. Personality (REEP), 9. Jelgava: LLU TF, 66-73. Retrieved from http://lufb.llu.lv/conference/REEP/2016/Latvia-Univ-Agricult-REEP-2016proceed2255-808X.pdf

9. Greenblatt E. (2002). Work/Life balance: wisdom or whining. Organizational Dynamics, 31(2), 177 - 193.

10. Greenhouse J.H., Powell G. (2006). When work and family are allies: a theory of work - family enrichment. Academy of Management Review, 31(1), 72 - 92.

11. Haeger D., Lingham T. (2014). A trend toward Work - Life Fusion: a multi-generational shift in technology use at work. Technological Forecasting and Social Change, 89, 316 - 325.

12. Ilies R., Wilson K.S., Wagner D.T. (2009). The spillover of daily job satisfaction onto employees' family lives: the facilitating role of work-family integration. Academy of Management Journal, 52 (1), 87 - 102.

13. Khallash S., Kruse M. (2012). The future of work and work - life balance 2025. Futures, 44 (7), 678-686.

14. Kumar H., Chakraborty S.K. (2013). Work life balance (WLB): a key to organizational efficacy. Prin. $L N$ Welingkar Institute of Management Development and Research, 15 (1), 62-70.

15. Lockwood N.R. (2003). Work/life balance: Challenges and solutions. Society for Human Resources Management: Research Quarterly, 2, 1-12.

16. Rama Devi V., Nagini A. (2013). Work-life balance and burnout as predictors of job satisfaction in private banking sector. Skyline Business Journal, 9(1), 50-53.

17. Vogt W.P. (2005). Dictionary of Statistics and Methodology: A Nontechnical guide for the social sciences (3rd ed.). Thousand Oaks, California: Sage Publications, Inc.

18. Whinston S.C., Cinamon R.G. (2015). The work - Family interface: integrating research and career counselling practice. The Career Development Quarterly, 63(1), 44 - 56. 